\title{
Essential newborn care practice and associated factors among health care providers in Northeast Ethiopia: a cross- sectional study
}

Gebrehana Ashenef ${ }^{1}$, Akine Eshete ${ }^{2}$, Betregiorgis Zegeye ${ }^{3}$, Tadesse Tsehay Tarekegn ${ }^{4}$ and Mitku Mammo Taderegew ${ }^{5^{*}}$ (1)

\begin{abstract}
Background: Globally, 2.7 million children die during the neonatal period annually. Ethiopia is one of the ten countries with the highest number of neonatal deaths. The practice of poor essential newborn care contributes to the problem. Hence the study was conducted to assess the essential newborn care practice and associated factors among health care providers from selected health facilities in Northeast Ethiopia.

Methods: Facility-based cross-sectional study was conducted among health care providers working in selected health facilities in Northeast Ethiopia from February-25 to March-25, 2019. Data were collected by a pre-tested questionnaire and an observational checklist. Then data were edited into Epi-data-7.2.0.1 and analyzed by using SPSS-25 software. The degree of association was assessed using binary logistic regression analysis. $P$-value $<0.05$ was considered statistically significant.

Results: A total of 256 health care providers were included in the study. Overall, $62.9 \%$ (95\%Cl: 57.0-68.8\%), and 73.8\% (95\%Cl: 68.4-79.2\%) of the health care providers had adequate knowledge and good practice on essential newborn care activities, respectively. The presence of supportive supervision ( $A O R=2.09,95 \% \mathrm{Cl}=1.07-4.11$ ), the interest of health care providers to work at delivery room (AOR $=1.97,95 \% \mathrm{Cl}=1.00-3.88)$, and availability of vitamin-K (AOR $=4.81,95 \% \mathrm{Cl}=1.07-21.64)$ were significantly associated with essential newborn care practices.

Conclusions: A significant number of health care providers had inadequate knowledge and poor practice of essential newborn care. Availability of vitamin-K, the interest of the health care providers to work in the delivery room and the presence of supportive supervision were the factors affecting essential newborn care practice. Hence, giving in-service training, supportive supervision, and providing supplies should be strengthened to enhance essential newborn care activities.
\end{abstract}

Keywords: Practice, Essential newborn care, Health care providers, Ethiopia

\footnotetext{
*Correspondence: mitkumamo@gmail.com

${ }^{5}$ Department of Biomedical Sciences, College of Medicine and Health Sciences, Wolkite University, P.O. Box 07, Wolkite, Ethiopia

Full list of author information is available at the end of the article
}

C C The Author(s). 2021 Open Access This article is licensed under a Creative Commons Attribution 4.0 International License, which permits use, sharing, adaptation, distribution and reproduction in any medium or format, as long as you give appropriate credit to the original author(s) and the source, provide a link to the Creative Commons licence, and indicate if changes were made. The images or other third party material in this article are included in the article's Creative Commons licence, unless indicated otherwise in a credit line to the material. If material is not included in the article's Creative Commons licence and your intended use is not permitted by statutory regulation or exceeds the permitted use, you will need to obtain permission directly from the copyright holder. To view a copy of this licence, visit http://creativecommons.org/licenses/by/4.0/ The Creative Commons Public Domain Dedication waiver (http://creativecommons.org/publicdomain/zero/1.0/) applies to the data made available in this article, unless otherwise stated in a credit line to the data. 


\section{Background}

Globally, an estimated 2.5 million neonates die every year, approximately 7000 deaths every day. The majority of all neonatal deaths (75\%) occur during the first week of life, and close to one quarter dying within the first 24 $\mathrm{h}$ of life. Approximately $98 \%$ of neonatal deaths occur in developing regions $[1,2]$.

The risk of neonatal deaths is highest in Africa (41 deaths per 1000 live births). The sub-Saharan regions of Eastern, Western, and Central Africa have between 42 and 49 neonatal deaths per 1000 live births. Ten countries account for $67 \%$ of the total newborn deaths from the global total neonatal deaths. Ethiopia is ranked at the sixth among ten countries with the highest number of neonatal deaths $[3,4]$.

According to the Ethiopian Demographic and Health Survey-2019, one in every 34 children dies within the first month, one in every 23 children dies before celebrating the first birthday, and one in every 18 children dies before reaching the fifth birthday. Thus, neonatal deaths account for more than $70 \%$ of infants' mortality and about 55\% of under-five mortality [5].

Most of the newborn deaths were due to preventable or treatable causes that occur because of poor implementation of essential newborn care (ENBC), and up to two-thirds could be saved by providing essential care to the newborns [6, 7]. As delivery and the first few hours of life are a critical period for the further growth and development of infants, the future well-being of the child will be determined by the quality of care that the newborn receive. Evidence showed that children who die within the first 28 days of birth suffer from conditions and diseases associated with a lack of quality of care at birth or skilled care and treatment immediately after birth and on the first day of life $[2,8]$.

Provision of immediate newborn care will prevent many newborn emergencies, meanwhile it can prevent $50 \%$ of complications and $45 \%$ of neonatal deaths which occur during birth and at postnatal periods [8-10]. Despite these, relatively little is known about the level of ENBC service delivery by health care providers and associated factors in Ethiopia particularly in the study area.

Thus, the finding of the study will provide baseline information on ENBC practice and its related factors which are helpful for policymakers, and other stakeholders to develop appropriate interventions towards improving newborns' health care delivery. The results will also benefit other researchers, as baseline data for further investigation. Hence the study was conducted to assess the practice of ENBC and associated factors among health care providers (Midwives, Nurse, General practitioners, Emergency surgeons, and Public health officers) in the health facilities of Northeast Ethiopia.

\section{Methods}

\section{Study design, and setting}

A facility-based cross-sectional study was conducted among health care providers working in the selected health facilities in the North Shoa administrative zone of Northeast Ethiopia from February-25-2019 to March-252019. North Shoa administrative zone is situated $130 \mathrm{~km}$ northeast of Addis Ababa, the capital city of Ethiopia. The administrative zone has 24 districts with a total of 9 government hospitals and 79 health centers (HC).

The study populations were all selected health care providers working in the selected hospitals and $\mathrm{HC}$ during the study periods. All the health care providers who were working in maternal and child health $(\mathrm{MCH})$ unit at selected health facilities were eligible for the study, whereas those health care providers who were assigned in $\mathrm{MCH}$ units but not participate in immediate newborn care activities during the study periods were excluded from the study.

\section{Sample size determination}

The required sample size of the study was estimated using a single population proportion formula, by considering: $P=81.1 \%$ (expected prevalence of essential newborns care practice among health care providers) [11], $95 \% \mathrm{CI}\left(\mathrm{Za} /{ }_{2}=1.96\right)$, and $5 \%$ margin of error. Then the minimum sample size obtained was 235. After adding a $10 \%$ non-response rate, a total of 259 health care providers were included in the study.

From all health facilities found in the district, six hospitals and $24 \mathrm{HC}$ were randomly selected using a lottery method. Then, the number of health care providers who were selected from each selected health facility was determined proportionally. Finally, a convenient sampling method was used to select each study participant in each selected health facility.

\section{Data collection procedures}

Data were collected using a semi-structured questionnaire and an observational checklist. The questionnaire and checklists were adopted from different literature with modifications for face-to-face interviews and clinical observation (Additional file 1: Table S1). The questionnaire contains variables for assessing sociodemographic characteristics, availability of supplies, and knowledge of health care providers towards essential newborn care. The practices of health care providers on essential newborn care were assessed by using an observational checklist while the health care provider performing newborn cares. .

Two data collectors and one supervisor from the nonselected hospitals and health centers were recruited for each selected health facility. After obtaining informed consent from each participant, information regarding 
sociodemographic characteristics, availability of supplies during their practice, knowledge, and practice of the participant towards ENBC were collected by data collectors.

To maintain the quality of the data, training was given for the data collectors and supervisors. The questionnaire was also pre-tested on $5 \%$ of the total sample size in a separate health facility. The questionnaire and data collection procedures were checked frequently for its consistency and completeness by the investigators and supervisor.

\section{Operational definitions \\ Knowledge}

Participants were considered as having good knowledge of essential newborn care if they scored greater than or equal to the mean score (8) of 16 knowledge-related questions. If they score below the mean score considered as having poor knowledge.

\section{Practice}

Refers to the practice of health care providers based on the prepared checklist regarding essential new-born care activities. Participants were considered as having good practice if they correctly perform at least $70 \%$ or above the tasks in the checklists. If they perform below $70 \%$ of the tasks in the checklist considered as having poor practice.

\section{Clean delivery room}

Separated room with at least one newborn care area for every 4 labor tables, and all surfaces were cleaned every morning and all equipment and surfaces were cleaned after every delivery [12].

\section{Statistical analysis}

Data were checked for completeness and consistency. Then data were entered into Epi-data-7.2.0.1 then analyzed by using SPSS-25 software. Categorical variables were stated in frequency using numbers (percentage) whereas the continuous variables were stated using means \pm standard deviation $(\mathrm{SD})$. Then the data were processed by using frequency distribution, and crosstabulation. Binary logistic regression analysis was used to identify factors associated with the practice of essential newborns care among health care providers. All independent variables with a $p$-value $<0.20$ in the bivariate analysis were entered into a multivariable regression model to control the effect of a confounder. The degree of association was measured by using the odds ratio (ORs) with 95\% CI. $P$-value with $<0.05$ was considered statistically significant.
Table 1 Socio-demographic characteristics of the study participants at Northeast Ethiopia, 2019 ( $N=256)$

\begin{tabular}{|c|c|c|}
\hline Variable & Frequency $(n=256)$ & Percentage (\%) \\
\hline \multicolumn{3}{|l|}{ Age (years) } \\
\hline$<25$ & 46 & 18.0 \\
\hline $25-29$ & 123 & 48.0 \\
\hline $30-34$ & 52 & 20.3 \\
\hline$\geq 35$ & 35 & 13.7 \\
\hline \multicolumn{3}{|l|}{ Marital Status } \\
\hline Married & 130 & 50.8 \\
\hline Single & 116 & 45.3 \\
\hline Divorced & 10 & 3.9 \\
\hline \multicolumn{3}{|l|}{ Religion } \\
\hline Orthodox & 229 & 89.4 \\
\hline Muslim & 13 & 5.1 \\
\hline Protestant & 14 & 5.5 \\
\hline \multicolumn{3}{|l|}{ Educational status } \\
\hline Diploma & 126 & 49.2 \\
\hline Degree & 111 & 43.4 \\
\hline Master & 13 & 5.1 \\
\hline Doctor & 6 & 2.3 \\
\hline \multicolumn{3}{|l|}{ Employment status } \\
\hline Midwife & 104 & 40.6 \\
\hline Nurse & 97 & 37.9 \\
\hline Doctor & 7 & 2.7 \\
\hline Emergency surgeon & 14 & 5.5 \\
\hline Health officer & 34 & 13.3 \\
\hline \multicolumn{3}{|l|}{ Work experience (years) } \\
\hline$<5$ & 145 & 56.6 \\
\hline $6-10$ & 71 & 27.7 \\
\hline $11-15$ & 25 & 9.8 \\
\hline$>15$ & 15 & 5.9 \\
\hline \multicolumn{3}{|l|}{ Monthly income (ETB) } \\
\hline$<3105$ birr & 45 & 17.6 \\
\hline 3105-3825 birr & 64 & 25.0 \\
\hline 3826-4545 birr & 53 & 20.7 \\
\hline$>4546$ & 94 & 36.7 \\
\hline
\end{tabular}

ETB Ethiopian birr

\section{Results}

Socio-demographic characteristics of the study participants

A total of 256 health care providers (with a response rate of 98.8\%) were recruited in the study, of which 153 (59.8\%) were males. Nearly half of the participants, 123 (48.0\%) were between the age of 25-29 years. The majority of participants, (89.5\%) were orthodox Christian. From the total of the study participants, 105 (41.0\%) 
Table 2 Assessment of different supplies and drugs available in the health facility for ENBC, practice in Northeast Ethiopia, 2019 $(N=256)$

\begin{tabular}{lll}
\hline Variables & Yes (\%) & No (\%) \\
\hline Are there different supplies and drugs being available in this health facility to provide ENBC? & $219(85.5)$ & $37(14.5)$ \\
Is there any internal or external supportive supervision regarding to ENBC? & $156(60.9)$ & $248(96.9)$ \\
Is there clean delivery room? & $252(98.4)$ \\
Availability of prepared cord tie & $241(94.1)$ \\
Is baby identification material prepared and available & $252(98.4)$ \\
Is suction device available in the health facility & $216(84.4)$ \\
Are there training guidelines available? & $245(95.7)$ \\
Vitamin K injection & $253(98.8)$ \\
TTC eye ointment & $62(24.2)$ \\
Trained about ENBC & $4(1.6)$
\end{tabular}

ENBC Essential newborns care, TTC Tetracycline eye ointment

were midwives and 96 (37.5\%) were nurse. One hundred seventy-nine $(69.9 \%)$ of the participants were working at the health center, $56(21.9 \%)$ were working at District hospitals and 144 (56.3\%) of them were interested to work in the delivery room (Table 1).

\section{Assessment of availabilities of supplies and drugs}

The majority (85.5\%) of participants stated that all the necessary supplies were available for running ENBC, and 156 (60.9\%) got supervision given by other health care providers or stakeholders as needed. The majority of the health care providers $183(71.5 \%)$ were not trained on basic ENBC but 216 (84.4\%) health care providers said that training guidelines of ENBC are available at their health facilities. The majority $(95.7 \%)$ of the health care providers said that Vitamin $\mathrm{K}$ injection is available at their health facility (Table 2).

\section{Assessment of the health care provider's knowledge regarding ENBC}

The majority (92.6\%) of the study participants stated that TTC eye ointment should be applied within $1 \mathrm{~h}$ of delivery, and 252 (98.4\%) of them said breastfeeding should be initiated within $1 \mathrm{~h}$ of delivery. About 251 (98\%) of the health care providers knew that colostrum helps to prevent newborn babies from infection.

Table 3 Knowledge of health professionals towards steps of immediate newborn care at different health facilities in Northeast Ethiopia, $2019(N=256)$

\begin{tabular}{|c|c|c|}
\hline Variables & Yes (\%) & No (\%) \\
\hline Is TTC eye ointment should be applied within $1 \mathrm{~h}$ of delivery? & $237(92.6)$ & $19(7.4)$ \\
\hline Should not the neonates be bathed immediately after birth if blood or meconium is stained on the skin? & $210(82.0)$ & $46(18.0)$ \\
\hline Is initiating breast feeding important for child if started within $1 \mathrm{~h}$ ? & $252(98.4)$ & $4(1.6)$ \\
\hline Should the neonates be referred when they develop complications immediately after birth? & $243(94.9)$ & $13(5.1)$ \\
\hline Does skin-to-skin contact prevent the newborns from hypothermia and help to stay warm? & $253(98.8)$ & $3(1.2)$ \\
\hline Is the newborn should be placed on the mother's abdomen immediately after birth? & $244(95.3)$ & $12(4.7)$ \\
\hline Is administering Vit K important to prevent bleeding? & $243(94.9)$ & $13(5.1)$ \\
\hline Is unable to suck or cry a newborn danger sign? & $242(94.5)$ & $14(5.5)$ \\
\hline All babies should be assessed after birth? & $248(96.9)$ & $8(3.1)$ \\
\hline Should you clean the face and eye of baby when the head of the neonate is delivered? & $249(97.3)$ & $7(2.7)$ \\
\hline Should the mothers be assessed after the delivery while she is on delivery coach? & $245(95.7)$ & $11(4.3)$ \\
\hline Is the colostrum prevents the neonates from infection and gives important nutrient? & $251(98.0)$ & $5(2.0)$ \\
\hline Is placing identification band on wrists or ankles mandatory? & $226(88.3)$ & $30(11.7)$ \\
\hline A newborn child should be bathed after $24 \mathrm{~h}$ even if the neonate has stained meconium? & $239(93.4)$ & $17(6.6)$ \\
\hline Are newborns should always be dry after birth? & $247(96.5)$ & $9(3.5)$ \\
\hline Are newborns should always be weighed after birth? & $253(98.8)$ & $3(1.2)$ \\
\hline
\end{tabular}


The majority (98.8\%) of the study participants knew that skin-to-skin contact of the newborn with the mother helps to prevent hypothermia and 210 (82.0\%) said that newborns should not be bathed immediately even if the baby has stained meconium. Overall, 62.9\% of participants had a good knowledge of essential newborns care practice (Table 3).

\section{Assessment of essential newborns care practice of the study participants}

In this study, the overall practice of ENBC was $73.8 \%$ (95\%CI: 68.4-79.2). Almost all the participants were applying cleaning the face and eye of the baby when the head is delivered. The majority (92.2\%) of them have checked the breathing of the baby and assesses the color of the newborn immediately after delivery. All of them apply to place the baby on the mother's chest for skinto-skin contact and initiate immediate breastfeeding. However, the majority of participants (82.0\%) didn't apply Chlorhexidine gel on the cord within $30 \mathrm{~min}$ of delivery (Table 4).

\section{Factors associated with the practice of essential newborns care}

In bivariate logistic regression analysis, age of participants, monthly income, work experience, the interest of the health care providers to work in the delivery room, type of the health facility, supportive supervision, availability of vitamin $\mathrm{K}$, and training of health care providers on ENBC had $p$-value $<0.20$ and candidate in multivariable logistic regression analysis.

In multivariable logistic regression analysis, the odds of practicing ENBC among participants who had got supportive supervision on ENBC was two (AOR $=2.09$, $95 \% \mathrm{CI}=1.07-4.11)$ times higher than those who hadn't.
Participants who were interested to work in the delivery room were also nearly 2 times $(\mathrm{AOR}=1.97,95 \% \mathrm{CI}=$ 1.00-3.88) more likely to have a good practice of ENBC. Furthermore, participants working in the health facility with the availability of Vitamin $\mathrm{K}$ were nearly five ( $\mathrm{AOR}=4.81,95 \% \mathrm{CI}=1.07-21.64)$ times more likely to have a good practice of ENBC (Table 5).

\section{Discussion}

In this institutional-based cross-sectional study, essential newborns care practice and its predictor among health care providers in northeast Ethiopia has been assessed. It was found that good practice of essential newborns care among health care providers was $73.8 \%(95 \% \mathrm{CI}=68.4-$ 79.2). It was also found that the practice of essential newborns care was significantly associated with the presence of supportive supervision, availability of vitamin K, and participants' interest to work in the delivery room.

The proportion of practice of ENBC in this study was almost similar to the study conducted at Tigray, northern Ethiopia (72.8\%) [13]. This similarity might be because the study in the Tigray region was recently conducted, both the region might have taken recently updated training on ENBC. However, in this study, the practice of the ENBC was higher than the study conducted in Sudan (58.9\%) [10], and Bahir Dar, Northwest Ethiopia (59.7\%) [14]. On the other hand, the practice of ENBC in this study was lower than the study conducted at Eastern Tigray (92.9\%) [15], and Addis Ababa, the capital city of Ethiopia (81\%) [16]. The possible explanation for these variations in the prevalence of essential newborns care practice might be due to the difference in the study setting, a possible slight difference in the data collection tools used, and the difference in the educational qualification of the study participants.

Table 4 Practice of health care providers on immediate newborn care at different health facilities in Northeast Ethiopia, 2019 ( $N=$ 256)

\begin{tabular}{|c|c|c|}
\hline Variable & $\begin{array}{l}\text { Tasks } \\
\text { performed (\%) }\end{array}$ & $\begin{array}{l}\text { Tasks not } \\
\text { performed (\%) }\end{array}$ \\
\hline Placed on the mother's abdomen, dry and stimulate neonate within $30 \mathrm{~s}$ after a vaginal delivery. & $254(99.2)$ & $2(0.8)$ \\
\hline Assess breathing and color after $30 \mathrm{~s}$ up to $1 \mathrm{~min}$ & $236(92.2)$ & $20(7.8)$ \\
\hline $\begin{array}{l}\text { The cord was clamped within 1-3 min when the baby does cry or breaths well. When the breaths was }<30 \\
\text { per minute, blue tongue, lips or trunk or gasping then resuscitating was immediately started. }\end{array}$ & $256(100.0)$ & $0(0.0)$ \\
\hline Chlorhexidine gel (4\%) was applied on the cord within 30 min of delivery & $46(18.0)$ & $210(82.0)$ \\
\hline $\begin{array}{l}\text { Place the infant in skin-to-skin contact on the mother's chest and cover both with clean linen and blanket as } \\
\text { required. }\end{array}$ & $256(100.0)$ & $0(0.0)$ \\
\hline Initiate breastfeeding immediately within $1 \mathrm{~h}$ & $256(100.0)$ & $0.0 \%$ \\
\hline Eye care-Apply tetracycline eye ointment within 90 min of delivery & $254(99.2)$ & $2(0.8)$ \\
\hline Give vitamin K, 1 mg IM on anterior mid-lateral thigh (within 90 min) & $251(98.0)$ & $5(2.0)$ \\
\hline Place the baby identification bands on the wrist and ankle (within 90 min) & $188(73.4)$ & $68(26.6)$ \\
\hline Weigh the newborn within 90 min \& when babies is stable and record all care given & $254(99.2)$ & $2(0.8)$ \\
\hline
\end{tabular}


Table 5 Multivariate analysis of factors associated with essential newborn care practice among health care providers in North shoa zone, Northeast Ethiopia, 2019 ( $N=256)$

\begin{tabular}{|c|c|c|c|c|}
\hline \multirow[t]{2}{*}{ Variable } & \multicolumn{2}{|l|}{ Practice } & \multirow[t]{2}{*}{ COR $(95 \% \mathrm{Cl})$} & \multirow[t]{2}{*}{ AOR $(95 \% \mathrm{Cl})$} \\
\hline & Good (\%) & Poor (\%) & & \\
\hline \multicolumn{5}{|c|}{ Monthly income (ETB) } \\
\hline$<3105$ & $35(77.8)$ & 10(22.2) & 1 & 1 \\
\hline $3105-3825$ & $47(73.4)$ & 17(26.6) & $0.79(0.32-4.93)$ & $1.28(0.46-3.62)$ \\
\hline $3826-4545$ & $33(62.3)$ & $20(37.7)$ & $0.47(0.19-1.16)$ & $1.03(0.33-3.27)$ \\
\hline$>4546$ & $74(78.7)$ & $20(21.3)$ & $1.06(0.49-2.95)$ & $2.15(0.65-7.12)$ \\
\hline \multicolumn{5}{|c|}{ Work experience (years) } \\
\hline$<5$ & 112(77.2) & $33(22.8)$ & 1 & 1 \\
\hline $6-10$ & $50(70.4)$ & 21(29.6) & $0.70(0.37-1.33)$ & $0.72(0.30-1.71)$ \\
\hline $11-15$ & $21(84.0)$ & $4(16.0)$ & $1.55(0.49-4.83)$ & $1.75(0.23-13.28)$ \\
\hline$>15$ & $6(40.0)$ & $9(60.0)$ & $0.19(0.65-0.59) *$ & $1.44(0.08-25.57)$ \\
\hline \multicolumn{5}{|c|}{ Interest to work in labor room } \\
\hline No & $72(64.3)$ & $40(35.7)$ & 1 & 1 \\
\hline Yes & 117(81.3) & $27(18.7)$ & $2.41(1.36-4.26) *$ & $1.97(1.00-3.88) *$ \\
\hline \multicolumn{5}{|l|}{ Health facility } \\
\hline Referral hospital & 17(80.9) & $4(19.1)$ & 1 & 1 \\
\hline District hospital & $51(91.1)$ & $5(8.9)$ & $2.40(0.58-9.98)$ & $2.86(0.58-14.23)$ \\
\hline Health center & 121(67.6) & $58(32.4)$ & $0.49(0.16-1.53)$ & $1.03(0.28-13.80)$ \\
\hline \multicolumn{5}{|c|}{ Presence of supervision } \\
\hline Absent & $65(65.0)$ & $35(35.0)$ & 1 & 1 \\
\hline Present & 124(79.5) & $32(20.5)$ & $2.09(1.26-3.90) *$ & $2.09(1.07-4.11) *$ \\
\hline \multicolumn{5}{|c|}{ Availability of Vitamin K } \\
\hline No & $3(27.3)$ & $8(72.7)$ & 1 & 1 \\
\hline Yes & 186(75.9) & $59(24.1)$ & $8.41(1.16-32.72) *$ & $4.81(1.07-9.64) *$ \\
\hline \multicolumn{5}{|c|}{ Age of health care providers (years) } \\
\hline$<25$ & $38(82.6)$ & $8(17.4)$ & 1 & 1 \\
\hline $25-29$ & $84(68.3)$ & 39(31.7) & 0.45(0.19-1.06) & $0.59(0.23-1.60)$ \\
\hline $30-34$ & $46(88.5)$ & $6(11.5)$ & $1.61(0.52-5.06)$ & 1.56(0.38-6.39) \\
\hline$\geq 35$ & $21(60.0)$ & 14(40.0) & $0.32(0.02-0.58) *$ & $0.06(0.04-1.07)$ \\
\hline \multicolumn{5}{|l|}{ Training on ENBC } \\
\hline No & 131(71.6) & $52(28.4)$ & 1 & \\
\hline Yes & $58(79.5)$ & $15(20.5)$ & $1.53(1.03-4.55) *$ & $1.52(0.65-3.54)$ \\
\hline
\end{tabular}

Note ( $\mathrm{N}=$ sample size; * $p$-value $<0.05$; Abbreviation: AOR Adjusted odd ratio, COR Crude odd ratio, D District, ETB Ethiopian birr

In this study, supportive supervision given for health care providers was significantly associated with the practice of ENBC which is similar to the study conducted in Jimma, Southwest Ethiopia [17] and Tigray, Northern Ethiopia [18] but unlike the study conducted in Jimma and Tigray in which knowledge and educational level were the determinants of ENBC, in this study knowledge and educational level were not significantly associated with the practice of ENBC. This difference might be due to the variations of the number of health care providers who received in-service training during supportive supervision.
In this study availability of vitamin $\mathrm{K}$ was significantly associated with the practice of ENBC but there was no significant association with the type of health facility. In the study conducted in the Tigray region besides the availability of materials, the type of health facility was significantly associated with the practice of ENBC [19]. This difference might be due to variation in in-service training and supportive supervision which was given for health care providers on ENBC in $\mathrm{HC}$ and hospitals. This increase in the practice of ENBC among health care providers in the health facilities with the availability of vitamin $\mathrm{K}$ may be an 
indication that the health facilities' preparedness for applying ENBC practice according to the recommended standards.

The interest of the health care providers to work in the delivery room was also significantly affecting the practice of essential newborn activities. Participants who were interested to work in the delivery room were nearly two times more likely to have a good practice of ENBC. This is similar to the study findings conducted in Jimma [17], and Wolaita zone [20]. This might be because health care providers who were interested to work in the delivery room may get more information and knowledge on areas where they are interested to work which can lead to an increment of the level of practice.

\section{Conclusion}

A significant number of health care providers had inadequate knowledge and poor practice on ENBC. Availability of vitamin $\mathrm{K}$, the health care providers' interest to work in the delivery room, and the presence of supportive supervision were the factors affecting ENBC. Hence, improving in-service training, supportive supervision, and providing supplies should strengthen to enhance ENBC activities.

\section{Limitations of the study}

Due to the cross-sectional nature of the study temporal and cause-effect relationship was not identified, and the study was not considering private health institutions were the limitations of the study.

\section{Abbreviations \\ AOR: Adjusted Odd Ratio; Cl: Confidence interval; COR: Crude Odd Ratio; ENBC: Essential newborn care; HC: Health Center; MCH: Maternal, newborn and child health; SPSS: Statistical Package for Social Science; TTC: Tetracycline eye ointment; WHO: World Health Organization}

\section{Supplementary Information}

The online version contains supplementary material available at https://doi. org/10.1186/s13690-021-00613-4.

Additional file 1: Table S1: English version questionnaire on essential newborn care practice and associated factors of among health care providers in Northeast Ethiopia: A Cross-Sectional Study.

\section{Acknowledgments}

We are grateful to the College of medicine and health science, Debre Berhan University, for logistic support for this study. We are also very grateful to each selected health facility staff for their teamwork in the study. Finally, our deepest gratitude goes to the study participants for providing the required information for this study.

\section{Authors' contributions}

AE: Participated in the conception, analysis, and interpretation of the results. GA: Participated in the conception, sample size calculation, and made major contributions to the study design and statistical analysis. BZH: Conceived the study, participated in the analysis and interpretation of the results, contributed to the writing of the manuscript. TाT: Participated in the conception, data entry and analysis, and writing of the results. MMT: participated in the study design, statistical analysis, and revised the manuscript. All authors contributed to the writing of the manuscript and approved the submitted version of the manuscript.

Funding

The authors received no financial support for this study and the study was funded by the authors.

\section{Availability of data and materials}

The datasets used and/or analyzed during this study are available from the corresponding author on reasonable request.

\section{Declarations}

\section{Ethics approval}

The study was conducted after ethical approval was obtained from the Ethical Review Board of Debre Berhan University. Permission was also taken from each institution's clinical director's offices. Then informed written consent was obtained from each health care provider. Confidentiality of the responses was ensured throughout the research process.

Consent for publication

Not applicable.

\section{Competing interests}

The authors declare that they have no competing interests.

\section{Author details}

${ }^{1}$ Department of Public Health, Debre Berhan Health Science College, Debre Berhan, Ethiopia. ${ }^{2}$ Department of Public Health, College of Health Science, Debre Berhan University, Debre Berhan, Ethiopia. ${ }^{3}$ Shewarobit Field Office, HaSET Maternal and Child Health Research Program, Addis Ababa, Ethiopia. ${ }^{4}$ Department of Nursing, College of Medicine and Health Sciences, Wolkite University, Wolkite, Ethiopia. ${ }^{5}$ Department of Biomedical Sciences, College of Medicine and Health Sciences, Wolkite University, P.O. Box 07, Wolkite, Ethiopia.

Received: 5 November 2020 Accepted: 21 May 2021

Published online: 01 June 2021

References

1. You D, Hug L, Ejdemyr S, Beise J, Idele P, Gerland P, et al. Child mortality 2015. 2015; https://www.unicef.org/media/files/IGME_report_2015_child_ mortality_final.pdf. Accessed 21 Jan 2019.

2. WHO, Newborn: reducing mortality, September 2019: https://www.who.int/ news-room/fact-sheets/detail/newborns-reducing-mortality. Accessed 28 Jan 2019.

3. World Health Organization. Neonatal and Perinatal Mortality. Country, Regional and Global Estimates. https://apps.who.int/iris/bitstream/handle/1 0665/43444/9241563206_eng.pdf?sequence=1\&isAllowed=y.

4. Adinew YM, Feleke SA, Mengesha ZB, Workie SB. Childhood mortality: trends and determinants in Ethiopia from 1990 to 2015 - a systematic review. Advances Public Health 2017;2017. https://doi.org/https://doi.org/1 0.1155/2017/7479295, 1, 10.

5. Demographic M, Survey H, Indicators K. Ethiopia Mini Demographic and Health Survey. 2019. https://dhsprogram.com/pubs/pdf/PR120/PR120.pdf.

6. Gurung G. Practices on immediate care of the newborn in the communities of Kailali district. Nepal Med Coll J. 2008;10(1):41-4 https://pubmed.ncbi.nlm. nih.gov/18700631/.

7. World Health Organization. Every Newborn: an action plan to end preventable deaths. https://www.who.int/publications/i/item/everynewborn-an-action-plan-to-end-preventable-deaths. Accessed 28 Jan 2019.

8. World Health Organization-2009. Newborn care until the first week of life: clinical practice pocket guide. https://apps.who.int/iris/bitstream/handle/1 0665/207705/9789290614562_eng.pdf. Accessed 17 Feb 2019.

9. Debelew GT, Afework MF, Yalew AW. Determinants and causes of neonatal mortality in Jimma zone, Southwest Ethiopia: a multilevel analysis of prospective follow up study. PLoS One 2014 Sep 18;9(9):e107184. https:// journals.plos.org/plosone/article/file?id=https://doi.org/10.1371/journal.pone. 0107184\&type=printable.

10. Ali F, Nasortaha R. Assessment of Knowledge, Attitude, and Practices of nurse-midwives towards immediate care of the newborn in Khartoum state 
teaching hospitals (2011). J Am Sci. 2013;9(9):263-70 http://www.jofamerica nscience.org/journals/am-sci/am0909/034_20235am0909_263_270.pdf.

11. Berhea TA, Belachew AB, Abreha GF. Knowledge and practice of essential newborn care among postnatal mothers in Mekelle City, North Ethiopia: a population-based survey. PLoS One 2018;13(8):e0202542. https://doi.org/ https://doi.org/10.1371/journal.pone.0202542.

12. Guideline for standardization of labor rooms at the delivery points. Maternal health division, ministry of health and welfare, the government of India. https://nhm.gov.in/images/pdf/programmes/maternal-health/guidelines/La bor_Room\%20Guideline.pdf. Accessed 21 Mar 2019.

13. Berhe AK, Tinsae F, Gebreegziabher G. Knowledge and practice of immediate newborn care among health care providers in eastern zone public health facilities. Tigray, Ethiopia, 2016. BMC pediatrics. 2017;17(1):157. https://bmcpediatr.biomedcentral.com/track/pdf/https://doi.org/10.1186/s12 887-017-0915-8, 17, 1, 157.

14. Yemaneh Y, Dagnachew E. Knowledge and practice of immediate newborn care (inc.) among health professionals in governmental health facilities of Bahir Dar city, North Ethiopia 2016. Qual Prim Care. 2017;25(6):360-7.

15. Misgna HG, Gebru HB, Birhanu MM. Knowledge, practice, and associated factors of essential newborn care at home among mothers in Gulomekada District, eastern Tigray, Ethiopia, 2014. BMC Pregnancy Childbirth 2016;16(1): 144. http://dx.doi.org/https://doi.org/10.1186/s12884-016-0931-y.

16. Wondaferash MT. Assessment of knowledge, attitude, and practice about immediate newborn care among health care providers in Addis Ababa public health centers. Ethiopian J Pediatrics Child Health. 2011;7(7):42-79 http://ejol.aau.edu.et/index.php/EJPC/article/view/745.

17. Negussie BB, Hailu FB, Megenta AD. Knowledge and practice of essential newborn care and associated factors among nurses and midwives working at health centers in Jimma zone, Ethiopia, 2016. J Nurs Care. 2018;7(446): 2167-8 Available at https:/www.researchgate.net/profile/Fikadu_Hailu/ publication/323555382

18. Weldeargeawi GG, Negash Z, Kahsay AB, Gebremariam Y, Tekola KB. Community-based essential newborn care practices and associated factors among women of Enderta, Tigray, Ethiopia, 2018. Int J Reproduct Med 2020 20;2020. https://doi.org/https://doi.org/10.1155/2020/2590705, 2027.

19. Gebru TT, Murugan R, Abrha AG, Goyteom MH. Knowledge and practice of immediate new-born care among midwives in central zone public health facilities, Tigray, Ethiopia: a cross-sectional study. BMC research notes 2019; 12(1):487. https://doi.org/https://doi.org/10.1186/s13104-019-4532-5.

20. Arba A, Zana Z. Knowledge of essential newborn care and associated factors among nurses and midwives: a cross-sectional study at public health facilities in Wolaita zone, southern Ethiopia, 2019. Int J Pediatr 2020 18;2020. https://doi.org/https://doi.org/10.1155/2020/3647309, 2028.

\section{Publisher's Note}

Springer Nature remains neutral with regard to jurisdictional claims in published maps and institutional affiliations.

Ready to submit your research? Choose BMC and benefit from:

- fast, convenient online submission

- thorough peer review by experienced researchers in your field

- rapid publication on acceptance

- support for research data, including large and complex data types

- gold Open Access which fosters wider collaboration and increased citations

- maximum visibility for your research: over $100 \mathrm{M}$ website views per year

At $\mathrm{BMC}$, research is always in progress.

Learn more biomedcentral.com/submissions 